\title{
A Meta-Analysis of Human-Wildlife Conflict: South African and Global Perspectives
}

\author{
Nimmi Seoraj-Pillai ${ }^{1,2, *}$ and Neville Pillay ${ }^{2}$ \\ 1 Department of Nature Conservation, Tshwane University of Technology, Private Bag X680, \\ Pretoria West 0001, South Africa \\ 2 School of Animal, Plant and Environmental Sciences, University of the Witwatersrand, Private Bag 3, \\ Wits 2050, South Africa; Neville.Pillay@wits.ac.za \\ * Correspondence: seorajpillayn@tut.ac.za; Tel.: +27-72-238-1404
}

Academic Editor: Shelley Burgin

Received: 4 October 2016; Accepted: 23 December 2016; Published: 28 December 2016

\begin{abstract}
Human-wildlife conflict (HWC), due to competition for shared natural resources between people and wildlife, influences food security of people and the well-being of people and animals. HWC is a major concern in developing countries, affecting people of different socio-economic classes. We conducted a meta-analysis of the occurrence of published scientific reports on HWC globally and South Africa particularly, to identify vulnerable human communities and their farming practices in developing and developed countries, and vulnerable wildlife guilds. We accessed Institute for Scientific Information publications from 1994 to 2015. Local communities (people living contiguous with protected natural areas) and commercial farmers jointly experienced the highest HWC incidences compared to subsistence farmers, possibly due to reporting bias for commercial farmers. Rural people in Africa and Asia experienced conflict with a diversity of mammals, confirming our expectation that developing countries could potentially experience regular encounters with wildlife. South Africa had more HWC cases than developed countries (e.g., in Australia and North America), yet the dichotomy between first world and third world economies in South Africa provides a regional exemplar of global patterns in HWC. Globally, HWC involved mainly mammals and birds, with carnivores and primates as the most high-scale conflict species and thus were a severely persecuted group. Our foundational research provides the first global assessment of HWC and showed that people in developing countries are vulnerable to HWC, perhaps related to reduced protection of livestock and crops against a larger guild of problem mammals. We suggest that a wider range of literature, including governmental and non-governmental publications, be surveyed to contribute to further research in this area of study.
\end{abstract}

Keywords: carnivores; high-scale conflict species; local communities; primates; subsistence farmers

\section{Introduction}

The escalating growth of the human population has increased demands for natural resources and fossil fuels [1]. During the 21st century, the human population has increased from 1.65 billion to 6.5 billion people, with a potential of reaching 8 billion people by 2025 [2,3]. As a result, human-dominated landscapes have intensified natural habitat degradation and fragmentation, and wildlife populations are now in regular competition with people for resources, thus eliciting human-wildlife conflict (HWC). In this study, HWC denotes any instance in which the resource demands of humans and wild animals overlap, spurring competition for food, space and water and thus creating tension between people and wildlife $[4,5]$. In addition, HWC threatens food security of people and the well-being of both people and wildlife [5].

Human-wildlife conflict is a global issue, afflicting both developed and developing countries $[5,6]$. Characteristics of HWC incidences are dependent on the type of resident wildlife in the region and 
the farming practices that are typical for that area. Wildlife in North America and Europe have been either extirpated or have experienced major geographic range collapses through hunting and persecution by people [5]. In most developed countries today, HWC is typified by large mammalian carnivores and commercial farmers $[7,8]$ because of extant wildlife assemblages and farming practices. Examples include the brown bear Ursus arctos, lynx Lynx lynx, gray wolf Canis lupus and wolverine Gulo gulo, all of which predominantly depredate commercially farmed sheep Ovis aries and/or cattle Bos taurus [7,8]. Such developed countries include Italy, Norway [8,9], the United States of America (USA) [7], Canada [10] and Australia [11,12].

Developing countries, such as India [13], Cameroon, the Central African Republic, Congo, Equatorial Guinea, Gabon [14], Uganda [15] and Bhutan [16], experience a wide variety of depredation by problem animals when compared with developed countries [6]. Examples include regular crop-raiding by non-human primates (hereafter primates), mega-herbivores (large-bodied herbivores), omnivores (e.g., wild boar Sus scrofa) and small mammals (e.g., cane rat Thryonomys swinderianus) [14,17]. Poultry depredation by mongoose Herpestes spp. and jackal Canis spp. are typical occurrences in Tanzania [18]. Human and livestock depredation in developing countries due to carnivores, for example, tiger Panthera tigris and the snow leopard Uncia uncia in India, leopard Panthera pardus in Zimbabwe, Tanzania and Pakistan and lion Panthera leo, are major sources of conflict $[19,20]$. Farmed game depredation by African wild dog Lycaon pictus (Gusset et al., 2008; Lindsey et al., 2005) are also common in developing countries, such as Zimbabwe [21,22], Botswana [23] and South Africa [21,22]. These occurrences suggest that the geographic distributions of wildlife populations together with farming practices are important predictors of HWC.

Currently, Africa has over 3000 protected areas (PAs), with approximately 50 biosphere reserves (i.e., PAs established to conserve the biological and cultural diversity of a region). Africa houses the world's largest reservoirs of wild animal populations in terms of density and diversity compared with the rest of the world $[24,25]$. Some scholars believe that these PAs were established at the cost of local livelihoods [25-27]. In the late 19th century, corresponding to outbreaks of rinderpest, unregulated hunting of wildlife and indigenous habitat clearing for farmland [28], urgent efforts to conserve natural resources and establish PAs were made by colonial governments [25,29]. It is estimated that about $50 \%$ of PAs worldwide have been established on land traditionally occupied and used by indigenous people [29]. Throughout Africa, thousands of indigenous people were evicted to accommodate the establishment of PAs $[25,27,30]$ and compressed into impoverished communities bordering PAs, and many of these communities exist still today [26]. Currently, the livelihoods of local human communities residing on the edge of these PAs often involve the direct exploitation of natural resources [26], bringing the communities into conflict with wildlife and park authorities.

According to the Food and Agricultural Organization (FAO) of the United Nations [31], Sub-Saharan Africa is dominated by smallholder subsistence farms, cultivating a mixture of crops corresponding to different soil and water regimes. Human pressure on soil health has left a third of all soils on which crop production depends degraded worldwide [32]. In Sub-Saharan Africa, $\sim 180$ million people are affected by land degradation [31,32] due to damaged soils that impede crop yields. Additionally, African pastoralist communities mostly live in remote and underdeveloped areas that are plagued by drought and disease [3]; therefore, these areas are associated with high levels of vulnerability to food insecurity [32]. Pastoral areas in Africa occupy about 40\% of Africa's land mass, with variations between countries [3]. Generally, pastoral areas are less suitable for crop production, and livestock husbandry remains the most common farming practice in arid regions of Africa [32].

South Africa is undergoing transition and reform with a contentious and distinct socio-economic and political history of racial segregation under the apartheid government $[27,33]$. South Africa is also a unique country of dualities in which first world, wealthy and stable industries and third world, underdeveloped sectors occur concurrently, and this is exemplified in the agricultural sector that comprises subsistence households and commercial farmers [34] farming within the same geographic area. Approximately 20\% (2.9 million) of all households in South Africa are subsistence 
households [35] that are compressed into racially segregated settlements in poor farming areas [25,27]. Commercial farmers dominate in particular provinces within South Africa, such as the Free State with $\sim 10,000$ farms, the Western Cape with $~ 8300$ farms and the North West Province with 7500 farms [35]. In contrast, Ebedes [36] reported that the approximately 7000 privately owned game farms in South Africa occupy 16 million hectares of land. Importantly, while commercial agriculture generates R30 billion ( US\$1.8 billion, where one South African Rand (ZAR) = US\$0.062) in profits annually, the game farming industry turnover accumulated R105 million ( US\$6.5 million) in the same period. In comparison, many of the households involved in subsistence agriculture, which far outnumber commercial and game farms, have limited income and depend on their farming efforts to ensure food security [35].

Most of the land in South Africa is only suitable for grazing (84 million hectares) and, due to soil aridity [37], only $13.5 \%$ can be used for crop production [25]. Commercial farming comprises livestock farming, game farming, field crops and horticulture [25]. Livestock keeping in South Africa consists predominantly of poultry and egg production, followed by red meat and dairy production, while crop and horticulture production predominantly consist of maize Zea mays, sugar cane Saccharum spp., potato Solanum tuberosum, wheat Triticum aestivum, and deciduous and citrus fruit [25,31].

In South Africa, several abiotic factors challenge farming efforts, namely decreasing soil fertility, low rainfall, increasing soil salinity and greenhouse gas emissions from livestock. Drought and famine have had devastating effects in southern Africa periodically [37]. The most severe droughts for the summer rainfall region of South Africa occurred in 1982/1983, with crop loss amounting to about R2.2 million ( US\$136,700), and resulting in a drop in the Gross Domestic Product (GDP) by 7\%. Similar impacts on GDP occurred in the 1992 drought [38]. During those periods of environmental stress, incidences of HWC also intensified. For example, the alleged damage caused by Chacma baboon Papio ursinus to timber plantations in South Africa increased during the 1982/1983 droughts, when these baboons utilised alternate food sources such as commercially farmed pine Pinus spp. trees. These incidences did not re-occur until the 1993/1994 droughts [39,40]. Environmental and climatic factors, therefore, increase opportunities for HWC, which manifest into crop and livestock damage $[39,40]$.

In South Africa, approximately $30 \%$ to $55 \%$ of poor, local community members reported HWC occurrences due to problem animals from neighbouring PAs [41]. Crop raiding by elephant Loxodonta africana and baboon and livestock depredation by lion and spotted hyena Crocuta crocuta were reported [41], and sporadic incidences involving large carnivore attacks on people were also documented [41]. Frequent episodes of crop-raiding were associated with harvest time, the most critical and vulnerable period for those impoverished households [41]. These findings indicate serious conservation and socio-economic issues that warrant further investigation.

There have been several international efforts to conserve cultural and natural amenities in developed countries, to increase the popularity of a destination through scenery and outdoor recreation [42]. Wildlife densities in such developed countries, however, remain low due to historical extirpations and several land-use changes (mining, farming, industrialisation) [43]. In contrast, developing countries in Africa contain $25 \%$ of the global mammal species, including about 80 species of antelope and $>2000$ bird species. In addition, Africa is home to $24 \%$ of the 34 global biodiversity hotspots [44]. South Africa, in particular, houses the third highest level of biodiversity globally [25] and presents a unique scenario to investigate HWC due to the prevalence of commercial farmers and local subsisting communities competing with PAs for critical natural resources.

The aim of our study was to investigate the occurrence of HWC globally and subsequently in relation to South Africa in order to assess common trends in vulnerable human populations, their farming practices and vulnerable wildlife guilds (e.g., carnivores and mega-herbivores). We adopted a broad approach because no study has previously considered HWC at a global scale or even considered the plight of affected communities in developing countries. We conducted a meta-analysis of published scientific literature from 1994 to 2015 indexed through the Institute for Scientific Information 
(ISI). Specifically, we (1) catalogued the global distribution of HWC from scientific publications; (2) assessed the numbers and types of HWC incidences experienced by different types of people (i.e., subsistence farmers, commercial farmers and local communities) in developed and developing countries; (3) identified damage-causing animals (DCAs); and (4) gauged the vulnerability of DCA species. We made three predictions: (1) Subsistence farmers/local communities would experience a higher number of depredation incidences than commercial farmers. This might be due to local communities' and subsistence farmers' close proximity to PA edges and the inability of poor households to afford wildlife-proof deterrents. (2) Mega-herbivores, primates and carnivores would feature prominently as DCAs in the literature. This might be due to their broad geographic distribution and their ability to transgress PA boundaries. Although small mammals can transgress boundaries, mega-fauna (large-bodied mammals) cause damage that is more noticeable over a short period. (3) Farmers in developing countries would be affected by a wider diversity of DCAs than farmers in developed countries. This might be due to the prevalence of dense and diverse wildlife reservoirs in, for example, Africa and Asia, and the inability of poor communities to afford fencing for their gardens and pastures.

\section{Materials and Methods}

\subsection{Literature Survey and Sourcing of Data}

A systematic review of the scientific literature on HWC was conducted using guidelines outlined by Pullin and Stewart [45] and Inskip and Zimmermann [46] with various search engines and data sources to establish the current scientific knowledge concerning HWC on a global scale and South Africa specifically. The review involved a pre-defined search protocol using filters for keywords to audit search relevance and applicability [45]. Literature containing the phrase 'human-wildlife conflict' was searched with Google Scholar (accessed June 2014 and July 2015). The initial search on Google Scholar alone yielded 206,000 search results. We thereafter limited searches to published scientific articles only, using the snowball method of reference harvesting from web-based search engines, such as the University of the Witwatersrand e-Wits Catalogue http://innopac.wits.ac.za/, http://www.jstor.org, www.elsevier.com; www.sciencedirect.com, link.springer.com/journals, and https://www.academicjournals.org. We further limited selection to published scientific articles containing two or more of the following keywords or phrases relevant to HWC in the title or abstract of each publication: human-wildlife conflict; mitigation; pastoralist; subsistence farming; commercial farming; communities; crop-raiding; livestock depredation; retaliatory killing; persecution; compensation; and attitudes and perceptions. This protocol ensured high levels of recall or relevance for a systematic review. We considered studies from 1994 onwards given the paucity of older HWC publications; since the 1800s until 1993, only five other publications with the phrase 'wildlife conflict' appeared in the title of the publication. Hence, we reviewed the literature for the past 22 years (1994 to 2015) only, which represented $98 \%$ of the literature with 'wildlife conflict' in the title of the publication since the 1800s.

Each publication that investigated a single DCA species/type (depending on detail), was recorded as a single incident per site. If the publication investigated more than one species of DCA, we considered each species as a separate incident per site. Hence, each DCA represented one data point. The collated literature was chronologically organised into a spreadsheet and examined under the following categories: author; year of publication; keywords; location; and Global Positioning System (GPS) co-ordinates of the study area (discussed later). Other categories examined included study species and conflict interfaces (i.e., subsistence farms, commercial farms and pooled farms-case studies where data for subsistence and commercial farmers were pooled and not compared) and local communities for scientific articles which did not specify whether or not people living adjacent to PAs farmed. 


\subsection{Mapping of Human-Wildlife Conflict Studies Using Geographic Information Systems}

For study sites where the GPS co-ordinates were not provided, these co-ordinates were obtained using an online geo-referencing tool (http:/ / www.gps-coordinates.net). In these cases, the midpoint of a PA or study site was used to derive their GPS co-ordinates. All GPS co-ordinates were converted to decimal degree format with latitude and longitude co-ordinates captured separately for importation into Quantum Geographic Information System (QGis) 2.8.1 (Quantum Geographic Information System Development Team, Wilmington, DE, USA) for geographic information system (GIS) analysis. The shape file was obtained from the South African National Biodiversity Institute (SANBI) and the Biodiversity Geographic Information System (BGIS) database [47]. The shape file was used as a base layer and opened first, onto which conflict study sites were overlaid. Hence, to examine the historic progression of studies concerning HWC, two separate maps were constructed to show studies from 1994 to 2000 and 2001 to 2015. To examine the distribution of different conflict species, GIS maps concerning species-level conflict were also generated in order to position the existing literature geographically. A separate map was also produced to examine the different groups of wild fauna studied from 1994 to 2015 in Sub-Saharan Africa only. This would highlight the HWC hot spots spatially.

\subsection{Gauging Species Vulnerability}

To assess species vulnerability to conflict and to gauge the predisposition or susceptibility of species for depredation, wildlife that appeared in the data set were divided into low-, moderate- and high conflict species. A description of how species were categorised for vulnerability and conflict status is provided in the Supplementary Materials (Table S1) using guidelines proposed by Gittleman et al. [48] and Inskip and Zimmermann [46]. These weightings considered the levels of biodiversity extinction vulnerability with corresponding acronyms for classification (Table S1). In their review of human-felid conflict, Inskip and Zimmermann [46] provided guidelines for gauging the index of vulnerability and the conflict status of carnivore pest species based on the number of times that a study species appeared in the literature (Table S2).

The cut-off levels provided in our study were adapted from Inskip and Zimmermann [46]. If a species appeared only once in the database, it was categorised as 'poorly researched' or 'low-scale conflict' (LSC) species and assigned the acronym PR for their vulnerability index. Low-scale conflict species are wild animals that rarely attack people, seldom depredate livestock or crops and experience rare retaliatory killings. Examples of LSC species include the sun bear Helarctos malayanus, black howler monkey Alouatta caraya, European rabbit Oryctolagus cuniculus, and greater flamingo Phoenicopterus roseus. If species appeared two to four times in the database, they were classified as a 'medium or moderately persecuted' (MP) animal or 'moderate-scale conflict' (MSC) species. Moderate-scale conflict species are wildlife that rarely attack people but may frequently depredate livestock or crops and experience frequent retaliatory killings, for example, the nilgai Nilgai Boselaphus tragocamelus, American black bear Ursus americanus, and Asiatic jackal Canis aureus. If animals appeared five or more times in the data set, such species were classified as a 'well researched' or 'high conflict' or 'severely persecuted' (SP) animal. High-scale conflict (HSC) species typically attack humans and experience high retaliatory persecution. Examples of HSC species include the African lion and brown bear. If such endangered species did not appear in the data set but anecdotal evidence of conflict existed, they were categorised as 'conflict status unknown' (SU), and that future research (FR) or research required (RR) should be conducted for such species (A list of acronyms are provided in the Glossary).

A species becomes vulnerable to extinction when it displays one or more of the seven characteristics [48,49]. These include: (1) reduction or severe fragmentation in its geographic range; (2) small, declining or low density population; (3) low reproductive rate; (4) large home range requirements; (5) reduced genetic variability; (6) special niche requirements; and (7) harvested by people for trophies, bush meat or pelts [48,49]. According to Gittleman et al. [48], these characteristics 
of vulnerability are important predictors of extinction risks and levels of species imperilment. We subsequently cross-referenced our data set to that of the International Union for Conservation of Nature (IUCN) Red List of Threatened Species to assess the conservation status of conflict species.

The level of taxonomic detail for species reported in each publication was inconsistent among publications in the database, with some authors providing species names and others only reporting the family name, for example, doves, family Columbidae. Hence, the detail in which our inventory of problem animals was documented depended on the level of detail provided in each publication. Therefore, we reported the types of mammals and birds that appeared in the review and where possible, provide the binomial scientific name.

\subsection{Statistical Analysis}

All statistical analyses were performed using R statistical software version 3.1.3 (R Foundation for Statistical Computing, Vienna, Austria) [50]). Bar plots were produced through the R software GrapheR extension version 1.9-84 (R Foundation for Statistical Computing, Vienna, Austria) [51]. For all tests, coefficient estimates, including the residual degrees of freedom (df), effect size, standard error, $Z$ statistic and corresponding $p$-values were generated through a generalised linear mixed model (GLMM) fit by maximum likelihood (with Laplace approximation) for both fixed and random effects using an lme4 extension [52] for fitting mixed-effects models. The GLMM with a Poisson error distribution is appropriate for analysing count data that do not assume a normal distribution. Although several methods to analyse meta-data exist, we used the GLMM because it allowed us to examine differences between and within regions. GLMMs were used to assess the impact of HWC on groups of people (local communities, subsistence and commercial farmers), because it is an extension to the generalized linear model, containing random effects (e.g., location) in addition to the typical fixed effects (e.g., subsistence and commercial farmers). In addition, the GLMM allows the specification of models whose response variable follows non-normal/error distribution (e.g., counts of literature studies (Poisson)), or binary distributions (yes/no or absent/present). Since the Poisson model assumes that the variance equals the mean, which is a concern for count data, we validated each model for potential overdispersion by implementing the $5 \%$ critical value for a chi-squared test against the residual degrees of freedom (df). Subsequently, we generated the scaled Pearson Chi-square statistic and examined whether this value divided by the $\mathrm{df}$ is $>1$. Where estimated dispersion was $>1$ the models were refitted using an extra-Poisson variation with inflated estimated variance or standard errors to adjust for overdispersion.

\subsubsection{The Vulnerability of People and Farming Commodities}

A GLMM with a Poisson error distribution and a log link function (e.g., for count data: number of publications, species, locations) was used to establish which types of people (fixed factors: subsistence farmers, commercial farmers and/or local communities) were more susceptible to depredation by low-, medium- or high-scale conflict species (dependent variables). The model evaluated differences between the types of people affected by HWC and, when such differences occurred, the GLMM relevel function showed the risk level or threat. All studies that discussed HWC management or policy frameworks but did not mention or include a specific study species were omitted from this analysis.

\subsubsection{Analysing Human-Wildlife Conflict Studies in South Africa in Relation to Global Studies}

We pooled the data of reported HWC incidences and the DCAs responsible for those incidences for South Africa and compared these with studies from the rest of Africa and elsewhere in the world. A GLMM model was used to establish differences between geographic areas or continents and, when such differences occurred (1994-2015), the GLMM relevel function evaluated the level of threat (i.e., country experiencing a greater number of HWC incidences). Relevel functions re-order factors of interest so that the level specified by reference is first and the others are moved down. This technique is useful for contrasts which take the first level as the reference. For example, first level factors included 
differences between countries, and second level factors examined and reordered factors to reveal countries experiencing greatest to lowest number of HWC incidences.

\subsubsection{Analysing Feeding Behaviour and Depredation Diet}

To investigate the relationship between natural feeding behaviour of DCAs and the type of product (e.g., crop, livestock, game or poultry) depredated, we compared the natural feeding habits of the animals with their depredation diet. Damage-causing animals that appeared in the database were classified into five categories: (1) herbivore, feeds on plant matter, including grain, seeds, modified rhizomes, stems, leaves, buds, flowers, fruits and lichen; (2) bulk grazer, herbivores that feed on large amounts of grass only; (3) bulk feeder, herbivores that feed on large amounts of browse/euphylls or grass, or a combination of both; (4) carnivore, feeds on animal matter mostly; and (5) omnivore, animal that feeds on fungi, carrion, plant and animal matter. These feeding habits were compared with the type of crop (livestock, poultry or a combination of these) depredated during each case study in the literature. Natural diet and feeding behaviour information were obtained from the Encyclopedia of Mammals [53], The Handbook of the Birds of the World [54] and Roberts' Birds of Southern Africa [55]. Although categories (1)-(3) are all herbivores, we distinguished between feeding types (1)-(3) because they differ in forage quality and quantity [56]. Species that only damaged property such as fences were excluded from the feeding habit analysis but were included in the vulnerability of people and South Africa analyses.

\section{Results}

\subsection{General Human-Wildlife Conflict Trends}

A total of 271 scientific publications concerning HWC in peer-reviewed journals from 1994 to 2015 were consulted. The data set of scientific publications for the meta-analysis constituted 220 research papers investigating DCAs worldwide, and the remaining 51 papers contained reports, discussions, policy frameworks and recommendations regarding HWC. Examination of the published articles revealed 38 incidences affecting subsistence farms, 93 incidences involving local communities, 67 incidences affecting commercial farms and 22 cases involving pooled subsistence-commercial farmer data (denoted as pooled farmer data). Under the search criteria, animals that appeared in the literature database (excluding species whose conflict status was classified as status unknown (SU)—see Table S1) comprised mainly mammals, including six types of antelope, 32 types of carnivores, five types of mega-herbivores, 25 types of primates and 15 types of species classified as other mammals. There were also 14 types of birds. The literature mostly reported mammals and birds whereas other taxonomic groups were under-reported. A comprehensive data set or inventory is available in Table S2. We pooled infrequently reported damage-causing mammals or non-specified damage-causing mammals into the group 'other mammals'.

\subsection{Vulnerability of People and Farming Commodities}

The data set showed that 45 different types of DCAs reportedly depredated subsistence farms, 49 different types of DCAs depredated local communities, 37 different types of DCAs reportedly depredated commercial farms and 25 different types of DCAs depredated on both subsistence and commercial farms (pooled farmers). A similar number of HWC cases were reported for commercial farmers and local communities, while a larger number of HWC cases were reported for commercial farmers compared with subsistence farmers and pooled farmers (Figure 1; Table 1). Similarly, local communities experienced a greater number of HWC incidences compared with pooled farmers and subsistence farmers, while subsistence farmers showed a greater number of HWC incidences compared with pooled farmers (Table 1). 


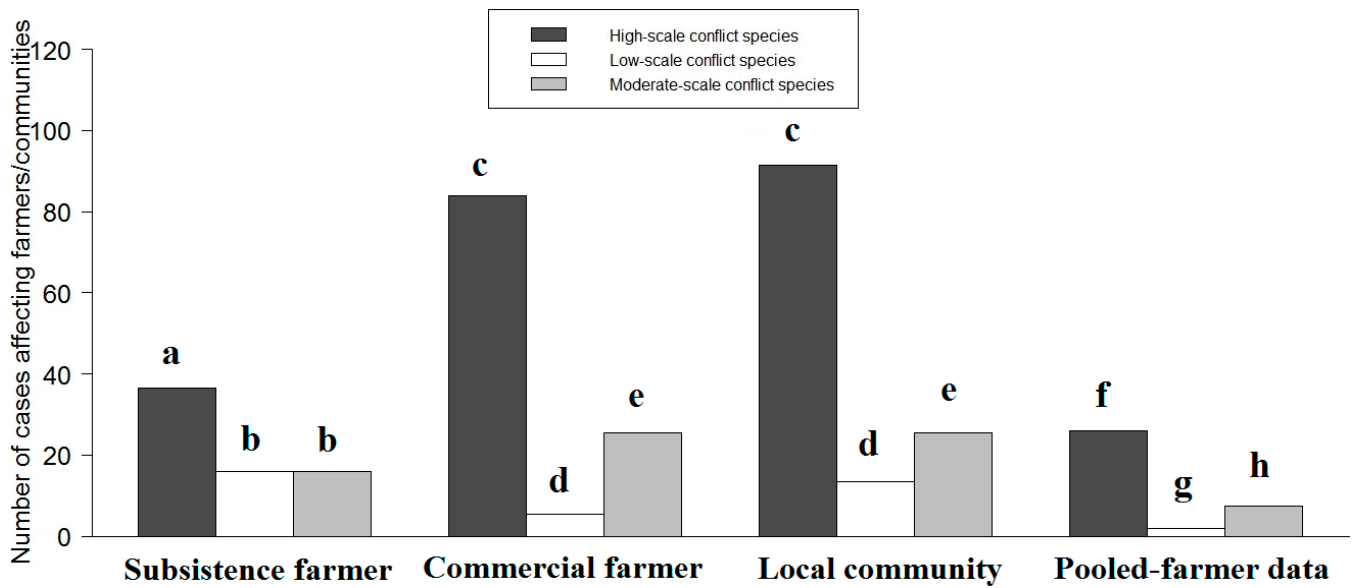

Figure 1. The prevalence of high-, low- and moderate-scale conflict species and type of farmer or community affected from 1994 to 2015. Bars denote total number of human-wildlife conflict cases generated during the meta-analysis. Different letters above bars (representing the $p$-values of the linear mixed models generated in Tables 1 and 2) denote significant differences between different types of people affected by high-, low- and moderate-scale conflict species.

Table 1. Generalised linear mixed model comparing how farmers and communities are affected by human-wildlife conflict worldwide. Model degrees of freedom, $\mathrm{df}=7$. The Poisson model displayed a moderate overdispersion parameter of 1.40 and the refitted model using an extra-Poisson variation is reported with adjusted standard errors.

\begin{tabular}{cccccc}
\hline Comparisons & $\begin{array}{c}\text { Farmer Experiencing Greater } \\
\text { Number of HWC Incidences }\end{array}$ & $\begin{array}{c}\text { Effect } \\
\text { Size }\end{array}$ & $\begin{array}{c}\text { Std. } \\
\text { Error }\end{array}$ & $\begin{array}{c}\boldsymbol{Z} \\
\text { Value }\end{array}$ & $p$ \\
\hline Commercial farmer vs. Pooled farmers & Commercial & -1.18 & 0.20 & -6.27 & $<0.001$ \\
Commercial farmer vs. Local communities & Similar & 0.10 & 0.14 & 0.82 & 0.410 \\
Commercial farmer vs. Subsistence farmers & Commercial & -0.52 & 0.16 & -3.51 & $<0.001$ \\
Local community vs. Pooled farmers & Local community & -1.28 & 0.20 & -6.90 & $<0.001$ \\
Local community vs. Subsistence farmers & Local community & -0.63 & 0.16 & -4.28 & $<0.001$ \\
Subsistence farmer vs. Pooled farmers & Subsistence farmer & -0.65 & 0.21 & -3.22 & $<0.001$ \\
\hline
\end{tabular}

Table 2. Statistical comparison of low (LSC)-, moderate (MSC)- and high-scale conflict (HSC) species affecting farmers and communities worldwide. Model degrees of freedom, $\mathrm{df}=8$. The Poisson model showed a moderate overdispersion parameter of 1.39 and the refitted model using an extra-Poisson variation is reported with adjusted standard errors.

\begin{tabular}{cccccc}
\hline Comparisons & Dominant Conflict Species & Effect Size & Std. Error & Z Value & $p$ \\
\hline LSC vs. HSC species & HSC & -1.84 & 0.18 & -10.69 & $<0.001$ \\
MSC vs. HSC species & HSC & 1.16 & 0.14 & -8.88 & $<0.001$ \\
LSC vs. MSC species & MSC & -0.68 & 0.21 & -3.37 & $<0.001$ \\
\hline
\end{tabular}

Cases involving high-scale conflict species were more common than moderate- and low-scale conflict species (Figure 1; Table 2). In addition, cases of moderate-scale conflict species were more common than low-scale conflict species (Figure 1; Table 2).

\subsection{Human-Wildlife Conflict Studies in South Africa versus Global Studies}

South Africa (number of HWC cases per DCA, $n=34)$ and Europe $(n=28)$ experienced similar trends in the number of HWC incidences in the literature (Table 3), whereas Asia $(\mathrm{n}=87)$ and other parts of Africa $(n=180)$ showed a greater number of HWC incidences per DCA when compared with South Africa (Table 3). South Africa experienced a greater number of HWC incidences per DCA compared with Australia $(n=3)$, South America $(n=13)$ and North America $(n=13)($ Table 3). 
Mega-herbivores, primates and other mammals did not differ in the numbers of HWC incidences in the database (Table 4). Carnivores were the main causes of damage, followed jointly by mega-herbivores and primates (Table 4). Interestingly, HWC cases in South Africa mainly involved commercial farmers.

Table 3. Statistical comparisons of human-wildlife conflict (HWC) incidences per damage-causing animal (DCA) reported from South Africa in comparison with the rest of the world. Model degrees of freedom, $\mathrm{df}=34$. The Poisson model displayed an overdispersion parameter of 3.70 and the refitted model using an extra-Poisson variation is reported with inflated standard errors.

\begin{tabular}{cccccc}
\hline $\begin{array}{c}\text { Comparisons } \\
(\mathbf{n}=\text { Number of HWC Cases per DCA) }\end{array}$ & $\begin{array}{c}\text { Country Experiencing Greater } \\
\text { Number of HWC Incidences }\end{array}$ & $\begin{array}{c}\text { Effect } \\
\text { Size }\end{array}$ & $\begin{array}{c}\text { Std. } \\
\text { Error }\end{array}$ & $\begin{array}{c}\boldsymbol{Z} \\
\text { Value }\end{array}$ & $p$ \\
\hline South Africa $(\mathrm{n}=34)$ vs. Asia $(\mathrm{n}=87)$ & Asia & 0.94 & 0.37 & 4.66 & $<0.001$ \\
South Africa vs. Australia $(\mathrm{n}=3)$ & South Africa & -2.43 & 1.08 & -4.05 & $<0.001$ \\
South Africa vs. Europe $(\mathrm{n}=28)$ & Similar & -0.19 & 0.40 & -0.76 & 0.450 \\
South Africa vs. North America $(\mathrm{n}=13)$ & South Africa & -0.96 & 0.55 & -2.96 & 0.003 \\
South Africa vs. Other parts of Africa $(\mathrm{n}=180)$ & Other parts of Africa & 1.67 & 0.72 & 8.95 & $<0.001$ \\
South Africa vs. South America $(\mathrm{n}=13)$ & South Africa & -0.96 & 0.55 & -2.96 & 0.003 \\
\hline
\end{tabular}

Table 4. Statistical comparison between damage-causing animals globally. Model degrees of freedom, $\mathrm{df}=35$. The Poisson model displayed an overdispersion parameter of 3.40 and the refitted model using an extra-Poisson variation is reported with inflated standard errors.

\begin{tabular}{cccccc}
\hline Comparisons & $\begin{array}{c}\text { Vertebrate Causing Greater } \\
\text { Number of Conflict }\end{array}$ & Effect Size & Std. Error & Z Value & $p$ \\
\hline Carnivore vs. Antelope & Carnivore & -3.20 & 0.48 & -8.91 & $<0.001$ \\
Carnivore vs. Bird & Carnivore & -2.33 & 0.32 & -9.76 & $<0.001$ \\
Carnivore vs. Mega-herbivore & Carnivore & -1.61 & 0.23 & -9.25 & $<0.001$ \\
Carnivore vs. Other mammals & Carnivore & -1.64 & 0.24 & -9.30 & $<0.001$ \\
Carnivore vs. Primates & Carnivore & -1.22 & 0.20 & -8.18 & $<0.001$ \\
Mega-herbivore vs. Antelope & Mega-herbivores & -1.58 & 0.52 & -4.10 & $<0.001$ \\
Mega-herbivore vs. Bird & Mega-herbivores & -0.72 & 0.38 & -2.58 & 0.010 \\
Mega-herbivore vs. Other mammals & Similar & -0.03 & 0.21 & -0.11 & 0.910 \\
Mega-herbivore vs. Primates & Similar & 0.40 & 0.28 & 1.93 & 0.060 \\
Other mammals vs. Antelope & Other mammals & -1.56 & 0.52 & -4.02 & $<0.001$ \\
Other mammals vs. Bird & Other mammals & -0.69 & 0.38 & -2.48 & 0.013 \\
Other mammals vs. Primates & Primates & 0.42 & 0.28 & 2.04 & 0.042 \\
Primates vs. Antelope & Primates & -1.98 & 0.49 & -5.28 & $<0.001$ \\
Primates vs. Birds & Primates & -1.12 & 0.35 & -4.24 & $<0.001$ \\
\hline
\end{tabular}

\subsection{Mapping of Human-Wildlife Conflict Studies}

From the distribution of reported sites of HWC (Figure 2), there was an $87 \%$ increase in reports of HWC in Africa and Asia from 2000 to 2015. In addition, there was a $92 \%$ increase in reports of HWC in South America (Figure 2). Interestingly, according to the search criteria outlined in the methodology, HWC in South Africa was only first documented in 2005 in an ISI-indexed journal. Maps illustrating the distribution of conflict species were generated (Figures S1-S5) using data accessed from the literature.

\subsection{Vulnerability of Conflict Species}

Six types of antelope (eland, kudu, musk deer, nilgai, roan and sitatunga) and 14 types of birds (blackbird, crane, crow, dove, flamingo, goose, golden eagle, green parrot, partridge, pigeon, raptors (unspecified), thrush, vulture and weaverbird) were classified as low- to moderate-scale conflict species (Table S3). Only the family names of most birds were reported in the literature. Carnivores comprised seven low-scale conflict species (African wild cat and Amur tiger, Ethiopian wolf, Florida black bear, Iberian lynx, red fox and sun bear), ten moderate-scale conflict species (American black bear, Asiatic black bear, Asiatic jackal, Asiatic wild dog/dhole, caracal, common jackal, grizzly bear, Himalayan black bear, Scandinavian wolverine and serval) and 15 high-scale conflict species (African lion, African wild dog, black-backed jackal, brown bear, brown hyena, cheetah, Eurasian lynx, gray wolf, jaguar, 
leopard, Other Carnivora (unspecified), puma, snow leopard, spotted hyena and tiger) (Table S3). Mega-herbivores comprised one high-scale conflict species (African elephant), two moderate-scale conflict species (Asian elephant and Cape buffalo) and two low-scale conflict species (Great Indian one horned rhino and hippopotamus). Other mammals contained three high-scale conflict taxa (bushpig, porcupine and wild boar), eight low-scale conflict taxa (aardvark, common genet, European Bison, European rabbit, feral domestic pig, mongoose, squirrel and sulawesi warty pig) and six moderate-scale conflict taxa (African civet, feral house mouse, honey badger, rodents (unspecified), rice field rat and warthog) (Table S3). The primates comprised 15 low-scale conflict species (agile mangabey, black and white colobus monkey, black howler monkey, boutourlini's blue monkey, buton macaque, grey-cheeked mangebey, kipunji forest monkey, long-tailed macaque, moloney's white-collared monkey, moustached guenon, patas monkey, pig-tailed macaque, red colobus monkey, sclater's monkey and thomas' leaf monkey), four moderate-scale conflict species (blue monkey, chacma baboon, rhesus macaque and yellow baboon) and five high-scale conflict species (chimpanzee, olive baboon, orangutan, red-tailed monkey and vervet monkey). All scientific names of vulnerable conflict species are listed in Table S3.

An assessment of the conservation status of conflict species yielded several high- to moderate-scale conflict species listed on the IUCN Red List [57]. Carnivores featured prominently, posing high-scale conflict and consisting of the African lion (vulnerable), African wild dog (endangered), brown hyena (near threatened), cheetah (vulnerable), jaguar (near threatened), leopard (vulnerable), snow leopard (endangered) and tiger (endangered). The dhole (endangered) and Himalayan black bear (vulnerable) experienced moderate-scale conflict with humans. Mega-herbivore and primate red-listed species posing high-scale conflict in the literature included the African elephant (vulnerable) and the orangutan (critically endangered) respectively, and the Asian elephant (endangered) showed moderate-scale conflict with humans. Although anecdotal evidence [58-60] suggests that the endangered hirola or hunter's hartebeest Beatragus hunteri, the amur leopard Panthera pardus orientalis and the northern muriqui Brachyteles hypoxanthus may elicit conflict with people and farmers due to competition for resources, no supporting evidence for such conflict appeared in the literature. Overall, carnivores were the dominant feeding group associated with depredation compared with all other feeding habits, followed by bulk feeders and herbivores (jointly) and then omnivores (Table 5). The following categories of damage occurred (Table 6): crop-raiding only; livestock depredation only; poultry depredation only; crop-human combined depredation; crop-livestock combined depredation; crop-livestock-human combined depredation; equid-human-livestock combined depredation; equid-livestock combined depredation; game-human-livestock combined depredation; game-livestock combined depredation; human-livestock combined depredation; and livestock-poultry combined depredation. In most cases, we could not assess the species of crop and livestock damaged through depredation due to a lack of detail reported in the literature. These deficiencies or inconsistencies in reporting prevented a livestock or crop species level assessment of damage. Two categories of depredation, namely crop-raiding damage and livestock-only damage, dominated over all other types of depredation (Table 6), accounting for the greatest number of HWC incidences. 


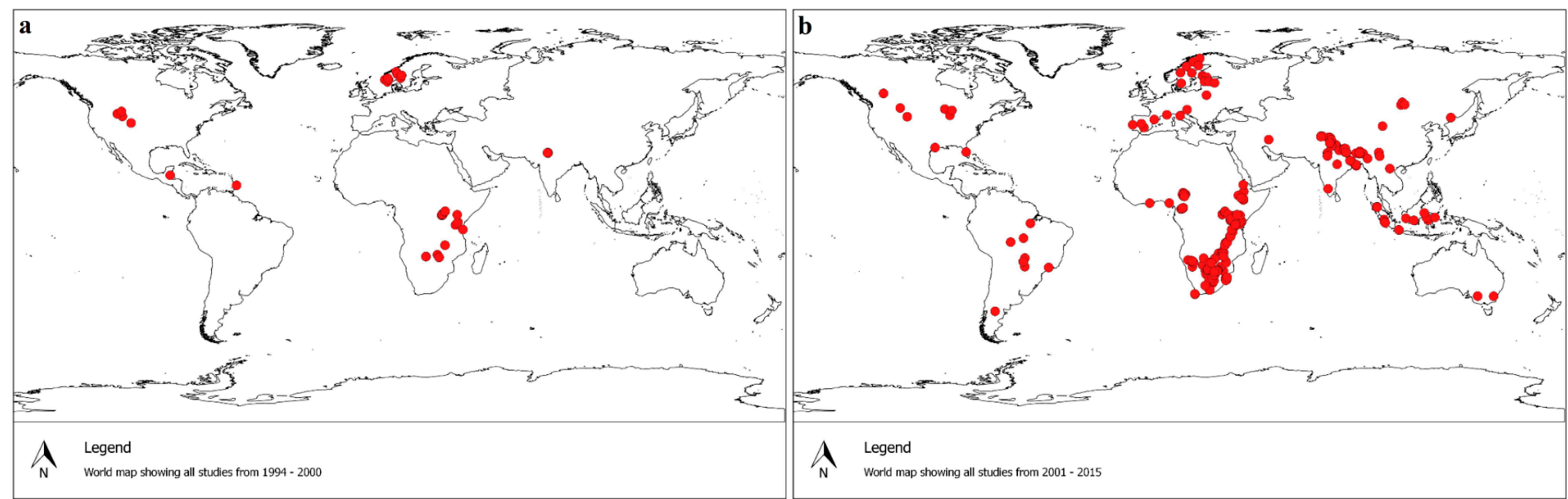

Figure 2. Comparison of the number of scientific publications concerning human-wildlife conflict in the published literature between (a) 1994-2000; and (b) 2001-2015. Red circles are global positioning system data points that represent human-wildlife conflict study sites, showing a substantial increase in publications of human-wildlife conflict in Africa and Asia over the two time periods and in previously under-reported South America. 
Table 5. Generalised linear mixed model showing the output of the dominant feeding habit associated with depredation through pair-wise comparisons. Model degrees of freedom, $\mathrm{df}=54$. The Poisson model displayed an overdispersion parameter of 3.40 and the refitted model using an extra-Poisson variation is reported with inflated standard errors.

\begin{tabular}{cccccc}
\hline Comparisons & $\begin{array}{c}\text { Dominant Feeding Habit } \\
\text { Associated with Depredation }\end{array}$ & Effect Size & Std. Error & Z Value & $p$ \\
\hline Bulk feeder vs. Bulk grazer & Bulk feeder & -2.14 & 0.70 & -4.08 & $<0.001$ \\
Bulk feeder vs. Carnivore & Carnivore & 1.62 & 0.25 & 8.71 & $<0.001$ \\
Bulk feeder vs. Herbivore & Bulk feeder & -1.58 & 0.55 & -3.84 & $<0.001$ \\
Bulk feeder vs. Omnivore & Omnivore & 0.84 & 0.27 & 4.15 & $<0.001$ \\
Bulk grazer vs. Carnivore & Carnivore & 3.76 & 0.67 & -7.50 & $<0.001$ \\
Bulk grazer vs. Herbivore & Similar & -0.56 & 0.83 & -0.90 & 0.370 \\
Bulk grazer vs. Omnivore & Omnivore & -2.98 & 0.70 & -5.87 & $<0.001$ \\
Carnivore vs. Herbivore & Carnivore & -3.20 & 0.51 & -8.38 & $<0.001$ \\
Carnivore vs. Omnivore & Carnivore & -0.78 & 0.17 & -5.77 & $<0.001$ \\
Herbivore vs. Omnivore & Omnivore & 2.42 & 0.52 & 6.20 & $<0.001$ \\
\hline
\end{tabular}

Table 6. Statistical comparison (GLMM) between categories of depredation exhibited by damage-causing wildlife. Model degrees of freedom, $\mathrm{df}=47$. The Poisson model displayed an overdispersion parameter of 6.57 and the refitted model using an extra-Poisson variation is reported with inflated standard errors.

\begin{tabular}{cccccc}
\hline Comparisons & $\begin{array}{c}\text { Greater Impacted } \\
\text { Variable }\end{array}$ & Effect Size & Std. Error & Z Value & $p$ \\
\hline Crop-raiding vs. Crop-Human & Crop-raiding & -2.67 & 0.65 & -6.36 & $<0.001$ \\
Crop-raiding vs. Crop-Livestock & Crop-raiding & -2.27 & 0.54 & -6.51 & $<0.001$ \\
Crop-raiding vs. Crop-Livestock-Human & Crop-raiding & -3.37 & 1.08 & -5.76 & $<0.001$ \\
Crop-raiding vs. Crop-Equid-Human-Livestock & Crop-raiding & -4.47 & 1.54 & -4.46 & $<0.001$ \\
Crop-raiding vs. Equid-Livestock & Crop-raiding & -4.47 & 1.54 & -4.46 & $<0.001$ \\
Crop-raiding vs. Game-Human-Livestock & Crop-raiding & -2.52 & 0.60 & -6.44 & $<0.001$ \\
Crop-raiding vs. Game-Livestock & Crop-raiding & -1.76 & 0.43 & -6.31 & $<0.001$ \\
Crop-raiding vs. Human-Livestock & Crop-raiding & -1.33 & 0.35 & -5.70 & $<0.001$ \\
Crop-raiding vs. Livestock & Similar & 0.26 & 0.22 & 1.84 & 0.070 \\
Crop-raiding vs. Livestock-Poultry & Crop-raiding & -1.13 & 0.34 & -5.24 & $<0.001$ \\
Crop-raiding vs. Poultry & Crop-raiding & -3.37 & 0.89 & -5.76 & $<0.001$ \\
Livestock vs. Crop-Human & Livestock & -2.93 & 0.65 & -7.04 & $<0.001$ \\
Livestock vs. Crop-Livestock & Livestock & -2.53 & 0.54 & -7.33 & $<0.001$ \\
Livestock vs. Crop-Livestock-Human & Livestock & -3.63 & 0.89 & -6.23 & $<0.001$ \\
Livestock vs. Crop-Equid-Human-Livestock & Livestock & -4.72 & 1.54 & -4.73 & $<0.001$ \\
Livestock vs. Equid-Livestock & Livestock & -4.72 & 1.54 & -4.73 & $<0.001$ \\
Livestock vs. Game-Human-Livestock & Livestock & -2.78 & 0.56 & -7.17 & $<0.001$ \\
Livestock vs. Game-Livestock & Livestock & -2.02 & 0.42 & -7.38 & $<0.001$ \\
Livestock vs. Human-Livestock & Livestock & -1.59 & 0.35 & -6.99 & $<0.001$ \\
Livestock vs. Livestock-Poultry & Livestock & -1.4 & 0.34 & -6.64 & $<0.001$ \\
Livestock vs. Poultry & Livestock & -3.63 & 1.08 & -6.23 & $<0.001$ \\
\hline
\end{tabular}

\section{Discussion}

\subsection{Vulnerability of People Affected by Human-Wildlife Conflict}

Local communities (i.e., people that might or might not farm) were reportedly depredated by 49 different species of wildlife globally, lending support that such communities are potentially the most common target for a wide range of damage-causing wildlife. These results were consistent with numerous other studies $[17,61]$ that suggest the susceptibility of local and subsistence communities to HWC. The findings concerning local communities also imply that HWC undermines household food security, especially in developing countries where farming operations are marginal and plagued by environmental crises such as desertification and drought [2,3]. Therefore, the effects of HWC will particularly amplify human hunger and malnourishment rates, typical of developing countries [12] that house millions of local communities on PA boundaries.

Our study supports our prediction that local communities would experience a higher number of depredation incidences than commercial farmers. However, these findings could be attributed 
to a greater reporting bias to commercial farming industries in the HWC literature. Moreover, the higher HWC-related damage reported in local communities could have been the result of many people reporting conflict rather than many actually experiencing more damage. In our study, local communities and commercial farmers experienced the highest numbers of HWC cases, which were dominated by high-scale conflict species. Our analyses of the literature did not yield any findings where scholars directly compared the impact of DCAs on subsistence and commercial farmers together. Hence, we suggest that a meticulous investigation and comparison is required on how subsistence and commercial farmers co existing in the same geographic area are impacted by and react to HWC.

\subsection{HWC in Developing Countries Versus Global Studies}

Our findings support the prediction that farmers in developing countries were affected by a wider diversity of DCAs than farmers in developed countries. African and Asian people experienced the highest number of HWC cases with all groups of wildlife compared with the rest of the world. Developing countries house greater biodiversity, more densely populated wildlife species and potentially more DCAs compared with developed countries [25], thus eliciting regular acts of depredation. In addition to a greater problem animal density, other elements that increase the frequency of depredation would be a lack of deterrents and preventative measures to conflict (e.g., farm fences, crop and livestock guards and shepherds) [62]. Such preventative measures are often unaffordable for farmers of developing countries, especially poor subsistence households [63].

South Africa was ranked as having one of the highest numbers of HWC cases $(n=34)$ caused by a distinct group of DCAs (especially carnivores, primates and mega-herbivores) when compared with the rest of the world, with the exception of Europe $(n=28)$ (discussed below). South Africa houses the third richest biodiversity in the world [25] and, therefore, the number of HWC cases documented could correspond to the species diversity of the region since, species-rich areas could potentially be vulnerable to regular HWC compared with the rest of world.

Similarities between the number of HWC incidences in the literature for South Africa and Europe could potentially be idiosyncratic, with novel research foci that do not extend to other geographic areas, particularly for HWC and commercial farming. Although the numbers of HWC incidences were similar for South Africa and Europe, it does not necessarily imply that this is due to similar wildlife assemblages. We believe that South Africa and Europe have experienced similar research emphases and reporting rates in scientific journals, particularly for commercial farmers, which seems to be the focus of current South African scholars.

\subsection{Geographic Distribution of Human-Wildlife Conflict Studies}

Our findings showed a substantial increase in publications of HWC in Africa and Asia since 2001. Trevers [64] attributed the growing attention and active research efforts in HWC from 1994 to 2015 as indicating how HWC issues have increased and intensified in occurrence and reported by both scholars and the public. Interestingly, between 1993 and 1999, Google Scholar returned 3100 hits for HWC compared with 8060 hits between 2000 and 2007 [64]. We acknowledge that our results were extracted from a meta-analysis and were subject to reporting bias. Such biases in the literature include model cases that focus on mammals predominantly. In addition, geographic patterns of HWC studies indicated that some African (including South Africa) and South American countries received increased scientific reporting on HWC from 2000 to 2015. These emergent geographic patterns of HWC studies correspond to rising efforts by global organizations such as the IUCN to address HWC and the associated challenges facing PA management [64,65]. It is likely that in the face of additional crises, such as global warming and food insecurity that contribute towards the intensity of HWC, scholars have identified deficits and urgent needs associated with addressing HWC.

Although European colonisation occurred throughout the world and shaped early conservation ideologies [25], apartheid laws were distinct to South Africa and contributed to a first world/third world dichotomy within the country $[25,27,66]$. Currently, about 3 million subsistence households [35] 
are contiguous with PAs [25,27]. These communities have been marginalised from PA management by conservation protectionist movements in South Africa [27,66]. Hence, our findings demonstrated that the first world/third world dichotomy within South Africa, coupled with the sum of disenfranchisement of rural people [67], could potentially intensify HWCs on the edge of PAs. Apartheid and concomitant European ideologies existed in South Africa until at least 1994 [25,27], and we speculate that such prejudiced principles continue today in practice but not policy. Therefore, it is plausible that the similar pattern between South Africa and Europe in HWC from 1994 to 2015 reflect idiosyncrasies aligned to European farming practices adopted by South African farmers. The first-world/third world dichotomy within South Africa is a theoretical possibility and requires elucidation, because, according to the findings of the meta-analysis, scholars have focused mostly on the (first world) commercial farmer.

\subsection{Vulnerability of Conflict Species}

Our results support the prediction that carnivores were frequent DCAs and the most high-scale conflict species reported globally $[6,46,62,68]$. Since high-scale conflict potentially leads to retaliation and contributes to the vulnerability of carnivores (also supported by the vulnerability index developed in our study), carnivores are a severely persecuted guild [6]. The leopard was the leading carnivore conflict species, featuring in the greatest number of human-carnivore conflict case studies. Leopard exhibit an array of biological and behavioural traits that render it high-impact conflict species $[5,69,70]$. This highly adaptable species occupies the broadest geographic range [69] and is better adapted to utilise human-dominated environments, such as farms, than other large predators [71,72].

The African lion, gray wolf Canis lupus and tiger also featured prominently in the literature with the joint second highest number of human-carnivore conflict incidences. Smaller carnivores, such as serval Leptailurus serval and jackal Canis spp., showed moderate- to high-scale conflict. Treves and Karanth [6] reported that carnivores (small and large) possess a long-standing history of competition with humans. Since free-ranging, large-bodied carnivores such as the African lion have been extirpated from farmland in South Africa [62,68,73], it does not account for livestock depredation. In contrast, leopard, cheetah, caracal and jackal frequently range freely in anthropogenic dominated landscapes [70-72,74] and were the leading depredators of small-medium livestock in southern Africa [70,74].

Consistent with our predictions that primates would cause high-scale conflicts due to their ability to transgress PA boundaries, five different primate species appeared in $\geq 5$ published papers in the literature. The results also demonstrated that a wide diversity of primate species showed moderate and low conflict with humans globally. Previous studies indicated baboons Papio spp. as exceptional examples that cause extensive damage to crops in Uganda and Ethiopia, and they were perceived by subsistence farmers as the greatest threats to crop yields $[17,75]$. Our findings that a large number of primate species were main DCAs are consistent with that of Estrada et al. [76] who showed that globally agricultural landscapes, such as orchards, crop farms and forestry plantations, were raided by approximately 57 different primate taxa in agro-ecosystems in which PAs and forestry or fruit plantations are contiguous. High levels of forest fragmentation and agricultural infringement were implicated as the cause of human-primate conflict [76]. The ability of primates to adapt to anthropogenic-dominated agricultural ecosystems and their often overlapping diets with humans brings them into conflict with farmers [76,77]. Additionally, our findings that primates and carnivores were high-scale conflict species, concur with several other studies $[6,46,53,62]$, that the threats facing felids, canids and primates are often identical and occur in the same region [78].

A large number of near threatened to endangered carnivores, two mega-herbivores (vulnerable African elephant and endangered Asian elephant) and one primate species, the critically endangered orangutan, showed high-scale conflict with humans. These species are an IUCN conservation priority, which coupled with HWC, could exacerbate their extinction risk. In addition, HWC poses serious threats and challenges to conserve these species outside PAs [6]. 
Notably, of the 17 cases where 14 different types of birds featured as the main DCA, the scientific name of only two species were reported (i.e., the blackbird Turdus merula and greater flamingo Phoenicopterus roseus). Although vultures were implicated in one case study, only the family name (Accipitridae) was reported, making it difficult to gauge whether vulnerable or threatened species were involved.

Overall, carnivores were the dominant feeding group associated with depredation when compared to all groups. Previous studies have shown that carnivores were prone to conflicts due to their large home ranges that overlap onto farmland and predation of livestock [79,80]. Human-carnivore conflict is likely to occur in areas in which the natural habitats of carnivores have been transformed into farmland and indigenous, natural prey species have been displaced by domestic livestock [80], especially those species that feed nocturnally and opportunistically, enabling them to exploit human-dominated environments [81,82]. Livestock damage as a leading category of depredation bears serious ramifications for livestock farmers $[81,83]$ and food security since livestock provides an important source of nutrition [31] and income [84] globally.

Interestingly, crop-raiding and livestock depredation jointly accounted for the greatest portion of HWC damage. Several other studies mention crop-raiding as a major problem throughout developing continents, such as Africa and Asia $[17,61,82]$. In Uganda, the most prominent wildlife crop raiders were African elephant, bushpig Potamochoerus sp., chimpanzee, olive baboon and red-tailed monkey [82]. All five of these species were categorised as high-scale, severely-persecuted conflict species in our analyses.

\section{Conclusions}

Our foundational research has provided the first global assessment of HWC, focussing on developing human communities. We showed that there were parallels and variations among HWC patterns worldwide. Developing countries had reportedly the highest incidences of HWC, mainly between local communities and a diverse array of mammals. In contrast, developed countries were characterised by fewer incidences of reported HWC and a reduced diversity of DCAs. South Africa, with its distinctive blend of first and third world practices, provides a regional exemplar of global trends in HWC. Carnivores and primates were prone to high-scale conflict globally, and they might be of conservation concern due to retaliation and retribution by people. Notably, vulnerable and critically endangered species, such as elephant and orangutan, require local level conservation management to ensure their persistence.

While our review has revealed several patterns in HWC, it has also highlighted gaps in our knowledge, requiring serious consideration in future studies. Systematic and in-depth examinations of the most vulnerable groups of people, identified here as local and subsistence farming communities bordering PAs, should be the focus of future HWC research avenues to assess food insecurity that exacerbate malnutrition on the one hand and vulnerabilities of wildlife through retaliation on the other hand. Reports concerning retaliatory practices and the occurrence of lethal control of problem species were deficient or omitted in many case studies. Lethal measures will severely affect species of conservation concern. The bias in reporting for larger mammal and birds requires elucidation through further research to account for the nature of the involvement of various taxonomic groups. We acknowledge that the data set may be biased towards English-speaking countries in addition to literature that uses specific terminology and not necessarily a representation of countries that applied uncharacteristic keywords and phrases. We also suggest that a wider range of literature, including governmental and non-governmental reports, that fall outside the mainstream of published literature be surveyed. In addition, the peer-reviewed literature concerning HWC does not necessarily reflect the current and most pertinent HWC issues in an impartial way. Scientific research on HWC is often performed by authorities from developed countries who nevertheless require grant support from organizations that dictate the problems to be investigated which are often not practical. We also acknowledge that gaps in the published literature does not necessarily imply that conservationists are 
ignorant or neglecting the issues, but a strong message needs to be made that people working with HWC issues (and who may be implementing new and appropriate mediatory practices to overcome HWC) need to publish their research. Finally, a meta-analysis approach has several limitations related to the lack of control of several factors that may potentially affect the reported counts of HWC, such as the distribution of human population densities, regional surface area, volume of research output across countries, the density of subsistence farming communities compared with commercial farmers and their access to HWC control measures, as well as the abundance of wildlife populations that vary widely regionally. We recommend that these factors be prioritised as important considerations to address the gaps in the literature.

\section{Glossary of Terms}

Apartheid. An official government policy of racial segregation formerly practised in South Africa, involving economic, legal and political discrimination against black individuals into second-class citizens who were restricted geographically, educationally, socially and professionally [66].

Commercial farmer. A farmer or enterprise that cultivates crops or produces livestock or game for sale with the objective of making a profit [31].

Conflict profile. A measure of the vulnerability of people and farming commodities to human-wildlife conflict based on the number of HWC cases reported in the published literature for such groups of people, in combination with the number of low-, moderate- or high-scale conflict species that commonly affect such groups of people.

Crop-raiding. The feeding or destruction of cultivated food by wild mammals and/or birds that causes significant loss of food and income to farmers [5].

Damage-causing animal (DCA). A free-living mammal or bird for which there is considerable evidence that it causes loss to livestock or game, or causes excessive damage to cultivated crops or poses a threat to human safety [5].

Depredation. The consumption of agricultural resources (crops, livestock and game) by free-living mammals and/or birds [5].

Developed (first world) country. An industrialised country with a well-developed economy and an advanced technological infrastructure relative to other less industrialised countries [12,31].

Developing (third world) country. A nation with an underdeveloped industrial base that is characterised by people with reduced life expectancy and lower income when compared with developed nations [12,31].

Edge. A boundary or interface between a protected area and a landscape element (human settlement or farmland) [85].

Food security. The state in which all people at all times have access to sufficient, safe, nutritious food to maintain a healthy and active life [31].

High-scale conflict species. Free-living mammals or birds that frequently (appear in five or more scientific papers according to Inskip and Zimmermann [46]) attack people and/or recurrently depredate livestock or crops, resulting in frequent retaliatory killings.

HWC hot spot. A biogeographic region in which significantly high incidences of human-wildlife conflict occurs [5].

Local community. People living adjacent to protected areas or reserves, who may or may not subsist through farming [26].

Low-scale conflict species. Free-living mammals or birds that rarely (appear at least once in a scientific publication according to Inskip and Zimmermann [46]) attack people, seldom depredate livestock or crops and rarely experience retaliatory killings.

Moderate-scale conflict species. Free-living mammals or birds that rarely (appear in two to four scientific papers according to Inskip and Zimmermann [46]) attack people but may frequently depredate livestock or crops and experience frequent retaliatory killings. 
Problem animal. A free-living, native wild mammal or bird whose natural behaviour, temperament or habits brings it into conflict with humans [5].

Protected area (PA). A biodiversity conservation area that receives protection due to the presence of indigenous fauna and flora that offers great ecological value [48].

Subsistence farmer. A farmer whose products are intended to provide for the basic needs of the farmer and his/her family with little surplus for marketing, bringing no profit (i.e., allowing for only a marginal livelihood) [31].

Wildlife. Undomesticated terrestrial vertebrate and invertebrate animals.

Supplementary Materials: The following are available online at www.mdpi.com/2071-1050/9/1/34/s1, Table S1: Description of categories that gauge vulnerability of human-wildlife conflict species and severity of conflict, Table S2: Problem animals that affected commercial farmers, local communities, subsistence farmers and pooled-farmers (subsistence and commercial farmers). Table S3: Vulnerability index and conflict status of problem animals that appeared in the human-wildlife conflict literature database, Figure S1: A species-level occurrence of published human-carnivore conflict from 1994 to 2015, Figure S2: A species-level occurrence of published human-primate conflict from 1994 to 2015, Figure S3: A species-level occurrence of published human-mega herbivore conflict from 1994 to 2015, Figure S4: A species-level occurrence of published human and other mammal conflict from 1994 to 2015, Figure S5: The distribution of publications concerning human-wildlife conflict in Sub-Saharan Africa from 1994 to 2015.

Acknowledgments: This study was supported by the National Research Foundation, South Africa (Thuthuka programme; grant number: TTK20110815000024620). We would like to thank Ivana Schoepf for her guidance with statistical analyses and for proofreading drafts of this manuscript. Grateful thanks are also owed to Sam Nicholson for assistance with GIS mapping.

Author Contributions: The descriptions of the contributions of the authors were as follows: Nimmi Seoraj-Pillai conducted data analysis, developed review concepts and the write-up. Neville Pillay conceived the ideas for this study, provided the theoretical approach for the review and commented on various drafts of the manuscript.

Conflicts of Interest: The authors declare no conflict of interest.

\section{References}

1. Boon, E.K. Food security in Africa: Challenges and prospects, regional sustainable review: Africa—Food security. In Encyclopedia of Life Support Systems (EOLSS); Developed Under the Auspices of the UNESCO; EOLSS Publishers: Oxford, UK, 2011.

2. Thornton, P.K.; Jones, P.G.; Ericksen, P.J.; Challinor, A.J. Agriculture and food systems in Sub-Saharan Africa in a $4{ }^{\circ} \mathrm{C}+$ world. Philos. Trans. R. Soc. A 2011, 369, 117-136. [CrossRef] [PubMed]

3. United Nations Development Programme (UNDP). Human Development Report 2007/2008: Fighting Climate Change: Human Solidarity in a Divided World; UNDP: New York, NY, USA, 2008.

4. Peterson, M.N.; Birckhead, J.L.; Leong, K.; Peterson, M.J;; Peterson, T.R. Rearticulating the myth of human-wildlife conflict. Conserv. Lett. 2010, 3, 74-82. [CrossRef]

5. Woodroffe, R.; Thirgood, S.; Rabinowitz, A. People and Wildlife: Conflict or Coexistence? Cambridge University Press: Cambridge, UK, 2005.

6. Treves, A.; Karanth, K.U. Human-carnivore conflict and perspectives on carnivore management worldwide. Conserv. Biol. 2003, 17, 1491-1499. [CrossRef]

7. Naughton-Treves, L.; Grossberg, R.; Treves, A. Paying for tolerance: Rural citizens' attitudes towards wolf depredation and compensation. Conserv. Biol. 2003, 17, 1500-1511. [CrossRef]

8. Vktersø, J.; Bjerke, T.; Kaltenborn, B.P. Attitudes towards large carnivores among sheep farmers experiencing different degrees of depredation. Hum. Dimens. Wildl. 1999, 4, 20-35. [CrossRef]

9. Vitali, C.A. frame-analytical perspective on conflict between people and an expanding wolf Canis lupus population in central Italy. Oryx 2014, 48, 575-583. [CrossRef] 
10. Treves, A.; Wallace, R.B.; Naughton-Treves, L.; Morales, A. Co-managing human-wildlife conflicts: A review. Hum. Dimens. Wildl. 2006, 11, 383-396. [CrossRef]

11. Burns, G.L. The fascination of fur and feathers: Managing human-animal interactions in wildlife tourism settings. Aust. Zool. 2006, 33, 446-457. [CrossRef]

12. World Bank. World Development Report 2013: Analyzing the World Bank's Goal of Achieving 'Shared Prosperity'; World Bank: Washington, DC, USA, 2013.

13. Chartier, L.; Zimmermann, A.; Ladle, R.J. Habitat loss and human-elephant conflict in Assam, India: Does a critical threshold exist? Oryx 2011, 45, 528-533. [CrossRef]

14. Barnes, R.F.W. The conflict between humans and elephants in the central African forests. Mamm. Rev. 1996, 26, 67-80. [CrossRef]

15. Hartter, J. Attitudes of rural communities towards wetlands and forest fragments around Kibale National Park, Uganda. Hum. Dimens. Wildl. 2009, 14, 433-447. [CrossRef]

16. Sangay, T.; Vernes, K. Human-wildlife conflict in the Kingdom of Bhutan: Patterns of livestock predation by large mammalian carnivores. Biol. Conserv. 2008, 141, 1272-1282. [CrossRef]

17. Hill, C.M. A conflict of interest between people and baboons: Crop-raiding in Uganda. Int. J. Primatol. 2000, 21, 299-315. [CrossRef]

18. Holmern, T.; Røskaft, E. The poultry thief: Subsistence farmers' perceptions of depredation outside the Serengeti National Park, Tanzania. Afr. J. Ecol. 2013, 52, 334-342.

19. Carter, N.H.; Riley, S.J.; Shortridge, A.; Shrestha, B.K.; Liu, J. Spatial Assessment of Attitudes Toward Tigers in Nepal. R. Swed. Acad. Sci. 2014, 43, 125-137.

20. Kesch, M.K.; Bauer, D.T.; Loveridge, A.J. Break on through to the other side: The effectiveness of game fencing to mitigate human-wildlife conflict. Afr. J. Wildl. Res. 2015, 45, 76-87.

21. Gusset, M.; Maddock, A.H.; Gunther, G.J.; Szykman, S.; Slotow, R.; Walters, M.; Somers, M.J. Conflicting human interests over the re-introduction of endangered wild dogs in South Africa. Biodivers. Conserv. 2008, 17, 83-101.

22. Lindsey, P.A.; Du Toit, J.T.; Mills, M.G.L. Attitudes of ranchers towards African wild dogs Lycaon pictus: Conservation implications on private land. Biol. Conserv. 2005, 125, 113-121. [CrossRef]

23. Schiess-Meier, M.; Ramsauer, S.; Gabanapelo, T.; König, B. Livestock predation- insights from problem animal control registers in Botswana. J. Wildl. Manag. 2007, 71, 1267-1274. [CrossRef]

24. Chape, S.; Harrison, J.; Spalding, M.; Lysenko, I. Measuring the extent and effectiveness of protected areas as an indicator for meeting global biodiversity targets. Philos. Trans. R. Soc. B 2005, 360, 443-455. [CrossRef] [PubMed]

25. DeGeorges, P.A.; Reilly, B.K. A Critical Evaluation of Conservation and Development in Sub-Saharan Africa: Last Chance Africa; Edwin Mellen Press: Lewiston, NY, USA, 2008; pp. 10-572.

26. Anthony, B.P. The dual nature of parks: Attitudes of neighbouring communities towards Kruger National Park, South Africa. Environ. Conserv. 2007, 34, 236-245. [CrossRef]

27. Cock, J.; Fig, D. From colonial to community based conservation: Environmental justice and the national parks of South Africa. Soc. Transit. 2000, 31, 22-35. [CrossRef]

28. Keller, D.R.; Golley, F.B. The Philosophy of Ecology: From Science to Synthesis; University of Georgia Press: Athens, Greece; London, UK, 2000; pp. 304-366.

29. MacKenzie, J.M. Empire and the ecological apocalypse: Historiography of the imperial environment. In Ecology and Empire. Environmental History of Settler Societies; Griffiths, T., Robin, L., Eds.; Keele University Press: Edinburgh, UK; University of Natal Press: Pietermaritzburg, South Africa, 1997; Chapter 14; pp. 232-248.

30. Carruthers, J. The Kruger National Park: A Social and Political History; University of Natal Press: Pietermaritzburg, South Africa, 1995.

31. Food and Agriculture Organization (FAO). World Agriculture: Towards 2015/2030. An FAO Perspective; FAO: Rome, Italy, 2015.

32. Roser, M. Land Use in Agriculture. Available online: http://ourworldindata.org/data/food-agriculture/ land-use-in-agriculture/ (accessed on 21 April 2015). 
33. Anthony, B.P.; Scott, P.; Antypas, A. Sitting on the fence? Policies and practices in managing human-wildlife conflict in Limpopo province, South Africa. Conserv. Soc. 2010, 8, 225-240. [CrossRef]

34. Armstrong, P.; Lekezwa, B.; Siebrits, F.K. Poverty in South Africa: A Profile Based on a Recent Household Survey; Stellenbosch Economic Working Papers 04/08; University of Stellenbosch: Stellenbosch, South Africa, 2008.

35. Statistics South Africa. Statistics South Africa Population Census 2011; Statistics South Africa: Pretoria, South Africa, 2011.

36. Ebedes, H. Preface. In Sustainable Utilisation-Conservation in Practice. Proceedings of the 5th International Wildlife Ranching Symposium; Ebedes, H.B., Reilly, B., van Hoven, W., Penzhorn, B., Eds.; Wildlife Decision Support Services: Pretoria, South Africa, 2001.

37. Turpie, J.; Winkler, H.; Spalding-Fecher, R.; Midgley, G. Economic Impacts of Climate Change in South Africa: A Preliminary Analysis of Unmitigated Damage Costs; Southern Waters Ecological Research \& Consulting \& Energy \& Development Research Centre, University of Cape Town: Cape Town, South Africa, 2002.

38. Rouault, M.; Richard, Y. Intensity and spatial extension of drought in South Africa at different time scales. Water S. Afr. 2003, 29, 489-500. [CrossRef]

39. Fergusson, R.A. Review of Baboons, Baboon Damage and Baboon Control in South African Plantation Forests with Particular Reference to Mpumalanga Province; Baboon Damage Working Group of South Africa: Sabie, South Africa, 2005.

40. Lamarque, F.; Anderson, J.; Furgasson, R.; Lagrange, M.; Osei-Owusu, Y.; Bakker, L. Human-Wildlife Conflict in Africa: Causes, Consequences and Management Strategies; Food and Agriculture Organization of the United Nations: Roman, Italy, 2009.

41. Spenceley, A. Nature-based tourism and environmental sustainability in South Africa. J. Sustain. Tour. 2005, 13, 136-170. [CrossRef]

42. Thorsell, J.; Sigaty, T. Human use in World Heritage natural sites: A global inventory. Tour. Recreat. Res. 2001, 26, 85-101. [CrossRef]

43. Hansen, A.J.; Rotella, J.J. Nature reserves and land use: Implications of the "place" principle. In Applying Ecological Principles to Land Management; Dale, V., Haeuber, R., Eds.; Springer: New York, NY, USA, 2001; pp. 57-75.

44. World Resource Institute. Available online: http://www.wri.org (accessed on 11 August 2016).

45. Pullin, A.S.; Stewart, G.B. Guidelines for systematic review in conservation and environmental management. Conserv. Biol. 2006, 20, 1647-1656. [CrossRef] [PubMed]

46. Inskip, C.; Zimmermann, A. Human-felid conflict: A review of patterns and priorities worldwide. Oryx 2009, 43, 18-34. [CrossRef]

47. Spatial Dataset. Available online: http://bgis.sanbi.org/SpatialDataset (accessed on 27 July 2015).

48. Gittleman, J.L.; Funk, S.M.; Macdonald, D.W.; Wayne, R.K. (Eds.) Carnivore Conservation; Cambridge University Press: Cambridge, UK, 2001.

49. Purvis, A.; Gittleman, J.L.; Cowlishaw, G.; Mace, G.M. Predicting extinction risk in declining species. Proc. R. Soc. B 2000, 267, 1947-1952. [CrossRef] [PubMed]

50. R Core Team. R: A Language and Environment for Statistical Computing; R Foundation for Statistical Computing: Vienna, Austria, 2015; Available online: http:/ /www.R-project.org/ (accessed on 4 June 2015).

51. Hervé, M. GrapheR: A multiplatform GUI for drawing customizable graphs in R. R J. 2011, 3, 45-53.

52. Bates, D.; Maechler, M.; Bolker, B.; Walker, S. Fitting linear mixed-effects models using lme4. J. Stat. Softw. 2015, 67, 1-48. [CrossRef]

53. Macdonald, D.W. The Encyclopedia of Mammals, 4th ed.; Oxford University Press: London, UK, 2009.

54. Del Hoyo, J.A.; Sargatal, A.E.J.; Christie, D.A. Handbook of the Birds of the World; Lynx Edicions: Barcelona, Spain, 2013; Volumes I-XVI.

55. Hockey, P.A.R.; Dean, W.R.J.; Ryan, P.G. (Eds.) Roberts' Birds of Southern Africa, 7th ed.; The Trustees of the John Voelcker Bird Book Fund: Cape Town, South Africa, 2005.

56. Owen-Smith, N. Functional heterogeneity in resources within landscapes and herbivore population dynamics. Lands. Ecol. 2004, 19, 761-771. [CrossRef]

57. International Union for Conservation of Nature (IUCN). Red List of Threatened Species. Version 2015-4. Available online: http:/ /www.iucnredlist.org/ (accessed on 6 July 2015).

58. Wikipedia. Hirola. Available online: https://en.wikipedia.org/wiki/Hirola (accessed on 13 July 2015). 
59. Wikipedia. Amur leopard. Available online: https://en.wikipedia.org/wiki/Amur_leopard (accessed on 13 July 2015).

60. Wikipedia. Northern Muriqui. Available online: https://en.wikipedia.org/wiki/Northern_muriqui (accessed on 14 July 2015).

61. Siex, K.S.; Struhsaker, T.T. Colobus monkeys and coconuts: A study of perceived human-wildlife conflicts. J. Appl. Ecol. 1999, 36, 1009-1020. [CrossRef]

62. Woodroffe, R.; Frank, L.G. Lethal control of African lions (Panthera leo): Local and regional impacts. Anim. Conserv. 2005, 8, 91-98. [CrossRef]

63. Hill, C.M.; Wallace, G.E. Crop protection and conflict mitigation: Reducing the costs of living alongside non-human primates. Biodivers. Conserv. 2012, 21, 2569-2587. [CrossRef]

64. Treves, A. The human dimensions of conflicts with wildlife around protected areas. In Wildlife and Society: The Science of Human Dimensions; Manfredo, M.J., Ed.; Island Press: Washington, DC, USA, 2006; Chapter 16; pp. 214-228.

65. Madden, F. Creating coexistence between humans and wildlife: Global perspectives on local efforts to address human-wildlife conflict. Hum. Dimens. Wildl. 2004, 9, 247-257. [CrossRef]

66. Khan, F. Rewriting South Africa's conservation history-The role of the Native Farmers Association. J. South. Afr. Stud. 1994, 20, 499-516. [CrossRef]

67. Adams, W.M.; Aveling, R.; Brockington, D.; Dickson, B.; Elliott, J.; Hutton, J.; Roe, D.; Vira, B.; Wolmer, W. Biodiversity conservation and the eradication of poverty. Science 2004, 306, 1146-1149. [CrossRef] [PubMed]

68. Potgieter, G.C.; Kerley, G.I.H.; Marker, L.L. More bark than bite? The role of livestock guarding dogs in predator control on Namibian farmlands. Oryx 2015, 50, 514-522. [CrossRef]

69. Kissui, B.M. Livestock predation by lions, leopards, spotted hyenas, and their vulnerability to retaliatory killing in the Maasai steppe, Tanzania. Anim. Conserv. 2008, 11, 422-432. [CrossRef]

70. Marker, L.L.; Dickman, A.J. Factors affecting leopard (Panthera pardus) spatial ecology, with particular reference to Namibian farmlands. S. Afr. J. Wildl. Res. 2005, 35, 105-115.

71. Di Minin, E.; Slotow, R.; Hunter, L.T.B.; Pouzols, F.M.; Toivonen, T.; Verburg, P.H.; Leader-Williams, N.; Petracca, L.; Moilanen, A. Global priorities for national carnivore conservation under land use change. Sci. Rep. 2016, 6, 23814. [CrossRef] [PubMed]

72. Nowell, K.; Jackson, P. Wild Cats Status Survey and Conservation Action Plan; IUCN/SSC/Cat Specialist Group: Gland, Switzerland, 1996.

73. Stadler, H. Historical perspective on the development of problem animal management in the Cape Province. In Proceedings of the Workshop on Holistic Management of Human-Wildlife-Conflict in the Agricultural Sector of South Africa, Ganzekraal Conference Centre, Western Cape, South Africa, 10-13 April 2006.

74. Avenant, N.L.; Du Plessis, J.J. Sustainable small stock farming and ecosystem conservation in Southern Africa: A role for small mammals? Mammalia 2008, 72, 258-263. [CrossRef]

75. Quirin, C.; Dixon, A. Food security, politics and perceptions of wildlife damage in Western Ethiopia. Int. J. Pest Manag. 2012, 58, 101-114. [CrossRef]

76. Estrada, A.; Raboy, B.E.; Oliveira, L.C. Agroecosystems and primate conservation in the tropics: A review. Am. J. Primatol. 2012, 74, 696-711. [CrossRef] [PubMed]

77. Bracebridge, C.E.; Tim, R.B.; Davenport, T.R.B.; Mbofu, V.F.; Marsden, S.J. Is there a role for human-dominated landscapes in the long-term conservation management of the critically endangered Kipunji (Rungwecebus kipunji)? Int. J. Primatol. 2013, 34, 1122-1136. [CrossRef]

78. Macdonald, D.W.; Burnham, D.; Hinks, A.E.; Wrangham, R. A Problem Shared Is a Problem Reduced: Seeking Efficiency in the Conservation of Felids and Primates. Folia Primatol. 2012, 83, 171-215. [CrossRef] [PubMed]

79. Linnell, J.D.C.; Swenson, J.E.; Andersen, R. Predators and people: Conservation of large carnivores is possible at high human densities if management policy is favorable. Anim. Conserv. 2001, 4, 345-349. [CrossRef]

80. Patterson, B.D.; Kasiki, S.M.; Selempo, E.; Kays, R.W. Livestock predation by lions (Panthera leo) and other carnivores on ranches neighbouring Tsavo National Parks, Kenya. Biol. Conserv. 2004, 119, 507-516. [CrossRef]

81. Holmern, T.; Nyanhongo, J.; Røskaft, E. Livestock loss caused by predators outside the Serengeti National Park, Tanzania. Biol. Conserv. 2007, 135, 518-526. [CrossRef] 
82. Naughton-Treves, L. Predicting patterns of crop damage by wildlife around Kibale National Park, Uganda. Conserv. Biol. 1998, 12, 156-168. [CrossRef]

83. Wang, S.W.; Macdonald, D.W. Livestock predation by carnivores in Jigme Singye Wangchuck National Park, Bhutan. Biol. Conserv. 2006, 129, 558-565. [CrossRef]

84. Sharma, R.K.; Bhatnagar, Y.V.; Mishra, C. Does livestock benefit or harm snow leopards? Biol. Conserv. 2015, 190, 8-13. [CrossRef]

85. Woodroffe, R.; Ginsberg, J.R. Edge effects and the extinction of populations inside protected areas. Science 1998, 280, 2126-2128. [CrossRef] [PubMed]

(C) 2016 by the authors; licensee MDPI, Basel, Switzerland. This article is an open access article distributed under the terms and conditions of the Creative Commons Attribution (CC-BY) license (http://creativecommons.org/licenses/by/4.0/). 